\title{
Transformations in the Grain Boundary Ensemble of M1 Copper Subjected to Equal-Channel Angular Pressing during Recrystallization Annealing
}

\author{
O. B. Perevalova ${ }^{a, *}$, E. V. Konovalova ${ }^{b}$, Yu. R. Kolobov ${ }^{c, d}$, and A. I. Korshunov \\ ${ }^{a}$ Institute of Strength Physics and Materials Science, Siberian Branch, Russian Academy of Sciences, \\ Tomsk, 634021 Russia \\ ${ }^{b}$ Surgut State University, Surgut, 628499 Russia \\ ${ }^{c}$ Institute of Chemical Physics Problems, Russian Academy of Sciences, Chernogolovka, 142432 Russia \\ ${ }^{d}$ Belgorod State National Research University, Belgorod, 308015 Russia \\ ${ }^{e}$ Russian Federal Nuclear Center, National Scientific Research Institute of Experimental Physics, Sarov, 607188 Russia \\ *e-mail: perevalova52@mail.ru
}

\begin{abstract}
The grain structure of M1 copper subjected to equal-channel angular pressing (ECAP) and subsequent annealing at $593 \mathrm{~K}$ for $1 \mathrm{~h}$ is studied by means of transmission electron microscopy and scanning electron microscopy with the diffraction of backscattered electrons. An increase in grain size and the formation of special boundaries ( $\Sigma 3$ twins both coherent and incoherent) are observed, along with the migration of highenergy $\Sigma 3$ twins and common grain boundaries, the splitting of $\Sigma 9$ special boundaries into $\Sigma 3$ twins, and the splitting of common grain boundaries into $\Sigma 9$ and $\Sigma 3$ special boundaries. The local transformation of common grain boundaries into special boundaries also occurs. Particles of the $\mathrm{Cu}_{2} \mathrm{O}$ phase are present on the migrating $\Sigma 3$ twins and common grain boundaries.
\end{abstract}

DOI: $10.3103 / \mathrm{S} 1062873818070304$

\section{INTRODUCTION}

Nanocrystalline (NC), sub-microcrystalline (SMC; grain size less than $1 \mu \mathrm{m}$ ), or ultrafine-grain structures (UFG; grain size is in the interval $1-10 \mu \mathrm{m}$ ) are produced in metals and alloys upon equal-channel angular pressing (ECAP). In the NC and SMC states, grain boundaries generally have high densities of defects $[1,2]$. Upon annealing by means of grain boundary diffusion, the grain boundaries migrate and transition to the equilibrium state [3]. The degree of nonequilibrium of grain boundaries in annealed copper after ECAP can be judged from their energy relative to the metal's surface energy [3]. It was found in [3] that when microcrystalline copper (99.98\%) is annealed at a temperature of $673 \mathrm{~K}$ for $15 \mathrm{~min}$, the grain boundaries remain nonequilibrium, while upon annealing at a temperature of $1073 \mathrm{~K}$ for $2 \mathrm{~h}$ they move into the equilibrium state. The increase in grain size in copper is accompanied by a reduction in the relative grain boundary energy [3].

The nature of recrystallization in SMC copper prepared via ECAP depends on the annealing temperature. Three stages can be distinguished on the curve of the dependence of grain size on the annealing temperature [4]. In the first of these, grain size does not depend on the temperature. In the second, there is abnormal grain growth (secondary recrystallization), with their size increasing from 0.5 to $10 \mu \mathrm{m}$. In the third stage, the grains grow to sizes larger than $10 \mu \mathrm{m}$, which is characteristic of the structure of large-crystal copper. The temperature intervals of each stage depend on the copper's degree of purity. The stage of abnormal grain growth in SMC copper is characterized by a sharp increase in the diffusion coefficient calculated using the kinetic parameters of recrystallization, compared to the corresponding values for the diffusion coefficient in collective recrystallization [4].

Alloy recrystallization after ECAP has a number of specific mechanisms, compared to the recrystallization of polycrystals with grain sizes larger than $10 \mu \mathrm{m}$ [5]. In nanocrystalline materials, grain growth is inhibited by the triple junctions of grain boundaries, the stable configurations of defects in grain boundaries, the generation of vacancies upon the merging of grain boundaries, and the presence of chemical inhomogeneities and dispersed particles of the second phase at grain boundaries. At the same time, the motive force of grain growth in these materials is considerably higher than in large-crystal ones, due to grain rotation and the high energy density associated with the presence of excess free volume [5]. 
(a)

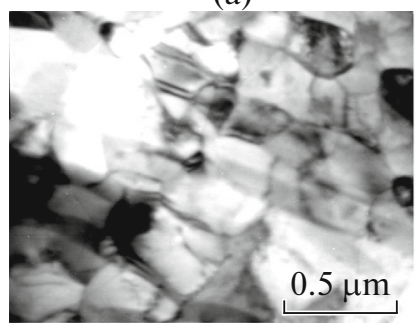

(b)

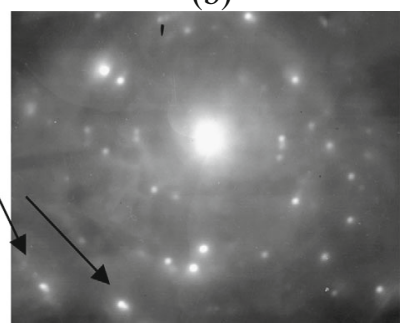

Fig. 1. Electron microscope image of the grain-subgrain structure of M1 copper subjected to ECAP: (a) light field, (b) microdiffraction. Arrows indicate reflections from subgrains with azimuthal disorientation.

The recrystallization of M00 pure copper $(99.96 \%)$ after rolling in the annealing process $(870 \mathrm{~K}, 2 \mathrm{~h})$ produces a polycrystal consisting of grains limited by common boundaries [6]. The contours of common boundaries are closed. Special boundaries, mostly $\Sigma 3$ twins, are found in certain parts of the grains. During primary recrystallization, common grain boundaries emerge where dislocation cells form during rolling [7]. In addition to common grain boundaries, $\Sigma 3$ twin boundaries are formed during primary recrystallization. The number of these depends on the degree of pre-deformation from rolling [8]. $\Sigma 3$ twins are formed via re-annealing during secondary recrystallization, due to inhomogeneities over the angle of disorientation along the boundaries of adjacent grains [9]. It was shown theoretically in $[9,10]$ that special boundaries are formed by the migration of common boundaries during annealing.

The aim of this work was to study the grain structure of M1 copper (99.9\%) subjected to ECAP (8 runs) with subsequent annealing at $593 \mathrm{~K}$ for $1 \mathrm{~h}$, and to compare it to the grain structure of coarse M00 copper subjected to rolling and subsequent recrystallization annealing.

\section{EXPERIMENTAL}

Optical metallography (OM), scanning electron microscopy with electron back-scattered diffraction (EBSD), and transmission diffraction electron microscopy (TEM) were used in this work. The energy of $\Sigma 3$ twin boundaries relative to the maximum energy of common boundaries was estimated using the Herring ratio [11].

Prior to ECAP, our M1 copper was in the polycrystalline state with an average grain size of $54 \mu \mathrm{m}$. The grains of the polycrystal contained with equal probability mesh, mesh-cellular, and cellular dislocation structures with an average dislocation density of $1.5 \times$ $10^{14} \mathrm{~m}^{-2}$ and nanocrystalline particles of the $\mathrm{Cu}_{2} \mathrm{O}$ phase on dislocations.

(a)

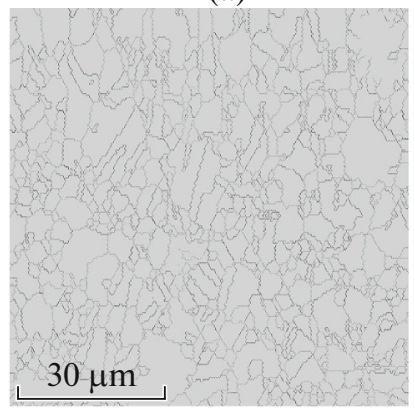

(b)

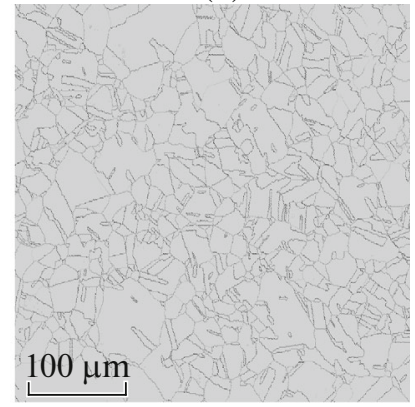

Fig. 2. EBSD maps of (a) the grain structure of annealed M1 copper subjected to ECAP; (b) annealed M00 copper after rolling deformation.

\section{RESULTS AND DISCUSSION}

After ECAP, both low- and high-angle grain boundaries (LAGBs and HAGBs) were present in the grain boundary ensemble of ultrafine M1 copper. According to EBSD data, their fractions were 0.6 and 0.4 , respectively [12]. According to TEM data, the elements of the grain-subgrain structure were elongated (Fig. 1a). Their average longitudinal and transverse dimensions were 0.4 and $0.2 \mu \mathrm{m}$, respectively. Microdiffraction patterns show reflections of asymmetrical shape, testifying to the presence of azimuthal disorientation at the boundaries of adjacent subgrains (Fig. 1b).

During the annealing of samples subjected to ECAP, ultrafine-grained structure was transformed into an inhomogeneous grain-subgrain structure with grain sizes in the interval of $0.8-12 \mu \mathrm{m}$. The LAGB fraction was 0.06; that of HAGB was 0.94. In addition to the anomalous growth of grains, there was restructuring of the grain boundary ensemble. The latter is clearly seen in our EBSD maps of grain structure (Fig. 2a). If HAGB consisted only of common boundaries before annealing, special boundaries formed after annealing. The vast majority of these were $\Sigma 3$ twins (Fig. 3a). In disordered polycrystalline solid solutions in the recrystallized state, the reciprocal density of coinciding nodes $\Sigma$ of physically separated (low-energy) special boundaries lay in the range $3 \leq$ $\Sigma \leq 11$ [11, 13]. Special boundaries with $\Sigma>11$ had energies close to those of common boundaries. We therefore analyzed the spectrum of special boundaries with $\Sigma$ values in the interval of $3 \leq \Sigma \leq 11$ for technically pure M1 copper, which is a solid solution of uncontrolled impurities of introduced and substituted elements in copper, although special boundaries with $\Sigma \leq$ 49 were determined via EBSD.

It can be seen from the distribution of the grain boundaries over the angles of disorientation (Fig. 4a) and the dependence of the fraction of special boundaries on the inverse density of coincident nodes (Fig. 3a) that the fractions of grain boundaries with 


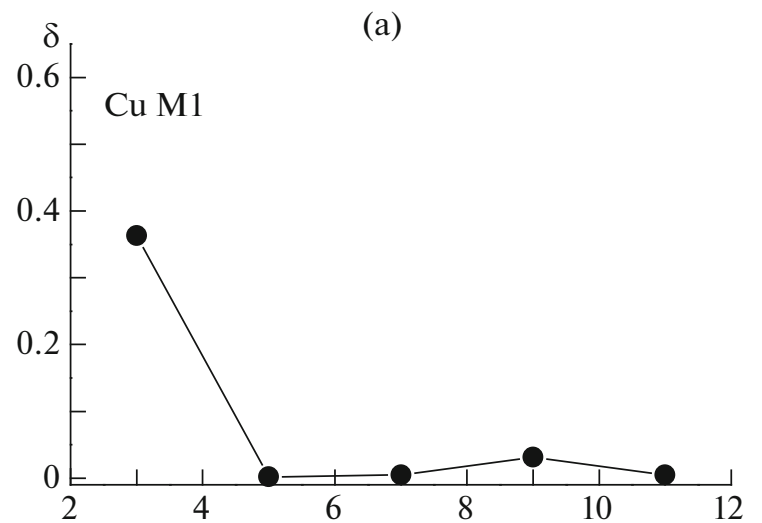

(b)

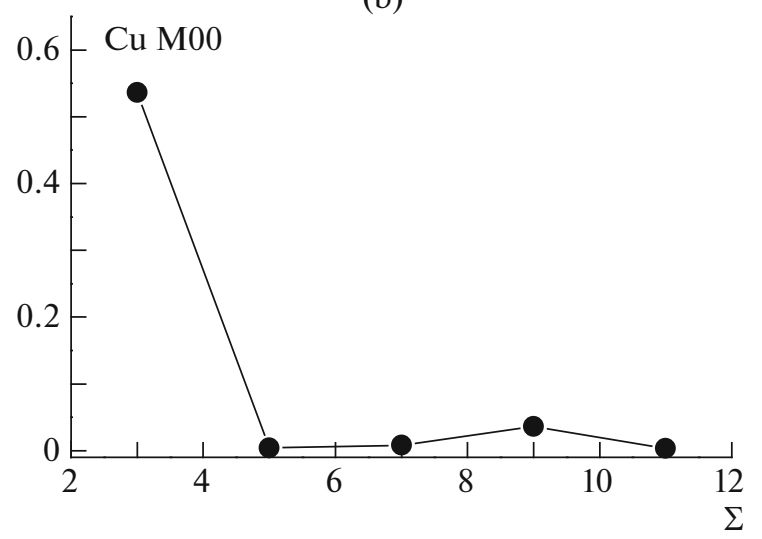

Fig. 3. Dependences of fraction $\delta$ of special boundaries in grain boundary ensembles on the inverse density of coinciding nodes $\Sigma$ (EBSD): (a) in annealed samples of M1 copper preliminarily subjected to ECAP; (b) M00 copper after rolling.

$60^{\circ}$ angles of disorientation and $\Sigma 3$ twins in the grain boundary ensemble of annealed M1 copper had similar values of around 0.4 .

The increase in grain size or distances between nearest grain boundaries during annealing is accompanied by a change in the type of their distribution from lognormal after ECAP to exponential after annealing. The change in the type of the distribution of distances between nearest boundaries is due to changes in the grain boundary ensemble during annealing, particularly the formation of $\Sigma 3$ twins and the reduction in the fraction of common boundaries. In pure $\mathrm{M} 00$ copper and $\mathrm{Cu}-\mathrm{Al}$ and $\mathrm{Cu}-\mathrm{Mn}$ alloys based on it, in the annealed state, the exponential type of distribution is characteristic of distances between special-special and common-special boundaries. Normal or lognormal distributions are characteristic of distances between common boundaries [14]. Even though the types of distributions between grain boundaries equally are due to the ratio of common and special boundaries in a grain boundary ensemble after annealing in both M00 and M1 copper previously subjected to ECAP, the topology of the polycrystal


Fig. 4. Distribution of grain boundaries as a function of disorientation angle: (a) in annealed samples of M1 copper preliminarily subjected to ECAP; (b) M00 copper after rolling (EBSD).

grain structure differs in them. In M00 copper with an average grain size of $12 \mu \mathrm{m}$, the boundaries of common grains form closed contours (Fig. 2b). In annealed M1 copper, the closed contour of common grain boundaries exists only in grains less than $0.8 \mu \mathrm{m}$ in size (Fig. 2a). There are no special boundaries inside such grains. Special boundaries are observed in grains larger than $0.8 \mu \mathrm{m}$. In these, it is impossible to distinguish a closed contour from common boundaries. In some local places, common boundaries are transformed into special boundaries. This shows that the formation of special boundaries during the annealing of ultrafine-grained copper occurs at the migration of common boundaries, accompanied by the rotation of grains.

The specificity of the grain boundary ensemble in annealed M1 copper compared to M00 copper becomes obvious when analyzing triple junctions in which at least one boundary is a $\Sigma 3$ twin. In M00 copper and its alloys, there is one type of triple junction with a $\Sigma 3$ twin. It consists of two common boundaries and one $\Sigma 3$ twin (first type) [11]. Among junctions of this type, those with a low-energy $\Sigma 3$ twin having a rel- 
Table 1. Fractions $\delta$ of different types of triple junctions (TJs) of grain boundaries among junctions containing $\Sigma 3$ twin boundaries in M00 copper and annealed M1 copper subjected to ECAP

\begin{tabular}{|c|c|c|c|c|}
\hline \multirow[b]{2}{*}{ Grade of copper } & \multicolumn{2}{|c|}{ TJ (two common boundaries $+\Sigma 3$ twin), $\delta$} & \multirow{2}{*}{$\begin{array}{c}\text { TJ (one common } \\
\left.\text { boundary }+ \text { two } \Sigma 3^{n} \text { twins }\right) \\
(n=1,2), \delta\end{array}$} & \multirow[b]{2}{*}{$\mathrm{TJ}(\Sigma 9+\Sigma 3+\Sigma 3)$} \\
\hline & $\begin{array}{c}\Sigma 3 \text { twins with energy } \\
0.02<\gamma_{\text {rel }}<0.1\end{array}$ & $\begin{array}{c}\Sigma 3 \text { twin with energy } \\
\gamma_{\text {rel }}>0.1\end{array}$ & & \\
\hline M1 & 0.30 & 0.41 & 0.15 & 0.14 \\
\hline M00 & $0.79[11]$ & $0.21[11]$ & - & - \\
\hline
\end{tabular}

ative energy in the interval of $0.02<\gamma_{\text {rel }}<0.1$ predominate (Table 1). The low-energy $\Sigma 3$ twins in disordered solid solutions and pure metals with fcc structure [15] are coherent twins lying in the (111) plane [11]. In annealed M1 copper subjected to ECAP, we observe the second type of junctions consisting of one common boundary and two $\Sigma 3^{n}$ twin boundaries $(n=1,2)$. There is also a third type of junction: those consisting of one $\Sigma 9$ twin and two $\Sigma 3$ twins. In half the junctions of the first type, $\Sigma 3$ twins are low-energy with relative energies of less than 0.1 . In the other half, they have energies greater than 0.1 (Table 1). Half of the $\Sigma 3$ twins in annealed M1 copper are thus incoherent twins.

For M00 copper and alloys based on it, and for pure metals with fcc structure (Al, Ni) [15, 16], austenite steel [17], and disordered $\mathrm{Ni}$ - and $\mathrm{Pd}$-based alloys [11], the $\Sigma 3$ twins observed on the surfaces of microsections in metallographic studies and EBSD, and on thin foils in TEM, are either rectilinear or faceted. The $\Sigma 3$ twins observed in annealed M1 copper preliminarily subjected to ECAP are rectilinear, faceted, or serpentine with curvilinear regions, and the latter have relative energies higher than 0.1. Analysis of EBSD maps of the grain structure shows that common boundaries on some sites are also serpentine. A serpentine line on the surface of a section is characteristic of migrating grain boundaries. When our M1 copper subjected to ECAP was annealed, common boundaries and high-energy $\Sigma 3$ twins thus migrated. However, this process was incomplete, and the serpentine shape of the common boundaries and $\Sigma 3$ twins was preserved up to the end of annealing. The presence of triple

(a)
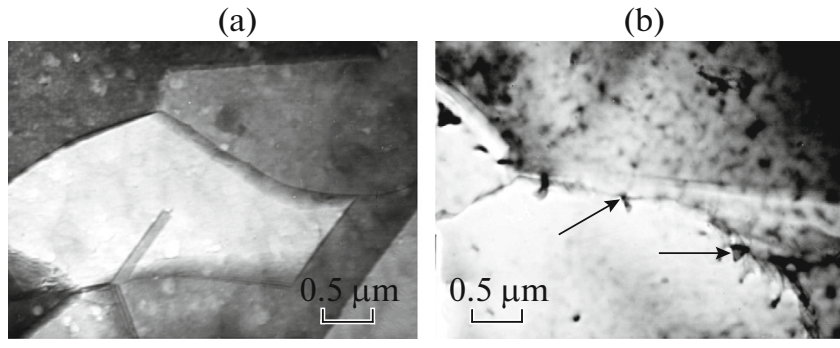

Fig. 5. (a) Electron microscope images of grain boundaries in annealed M1 copper subjected to ECAP, without second-phase particles and defects; (b) curvilinear grain boundaries with $\mathrm{Cu}_{2} \mathrm{O}$ particles. junctions of the second and third types testifies to the splitting of grain boundaries during annealing. Common boundaries split into two special boundaries, $\Sigma 3$ and $\Sigma 9$; the high-energy $\Sigma 9$ special boundaries, into two low-energy $\Sigma 3$ twins. Both types of splitting occurred with a reduction in the internal energy of the grain boundary ensemble. If the splitting of $\Sigma 9$ special boundaries into two $\Sigma 3$ twins was observed for pure metals in [18] and for solid solutions in [11, 19], or if multiple $\Sigma 3^{n} \rightarrow \Sigma 3^{n-1}+\Sigma 3$ twins were observed for nichrome in [19], the splitting of common boundaries into two special boundaries, $\Sigma 3$ and $\Sigma 9$, was observed for the first time in this work.

It was established via TEM that the low-energy $\Sigma 3$ twins in annealed M1 copper had no defects or nanocrystalline copper oxide particles (Fig. 5a), while copper oxide particles were observed on the fine-faceted serpentine boundaries that migrated during annealing (Fig. 5b). The presence of copper oxide particles obviously prevented the migrating $\Sigma 3$ twins from occupying the equilibrium position in the (111) plane. The separation of copper oxide particles on migrating grain boundaries could proceed during annealing. The oxide particles that existed before annealing could also be enveloped [20], fixing the serpentine shape of grain boundaries.

The fraction of $\Sigma 3$ twins in the grain boundary ensemble of annealed M1 copper was less than in M00 copper (Fig. 3b, 4b). Two factors can affect the fraction of $\Sigma 3$ twins: grain size and the stacking fault energy of the alloy. In our M1 copper, the average grain size was an order of magnitude smaller than in M00 copper. In $\mathrm{Ni}_{3} \mathrm{Fe}$ alloy with polycrystals having grain sizes of $40-250 \mu \mathrm{m}$, the fraction of $\Sigma 3$ twins in the grain boundary ensemble thus grew along with grain size [11]. In our M1 copper, oxygen was present both in the form of $\mathrm{Cu}_{2} \mathrm{O}$ oxide and in solid solution, which could change the stacking fault energy. For copper, the reduction in the stacking fault energy upon alloying was accompanied by an increase in the fraction of $\Sigma 3$ twins [11].

In pure metals, the ability of $\Sigma 3$ twins to migrate upon annealing is less than that of common boundaries [21]. The migration of incoherent $\Sigma 3$ twins in annealed M1 copper subjected to ECAP apparently testifies to a higher coefficient of grain boundary diffusion, com- 
pared to the corresponding one of recrystallization during the annealing of large-crystal copper.

\section{CONCLUSIONS}

Annealing at $593 \mathrm{~K}$ for $1 \mathrm{~h}$ of submicrocrystalline M1 copper obtained via equal-channel angular pressing led to the formation of an inhomogeneous grain structure that corresponded to the stage of the abnormal grain growth in the $d-T$ curve. A number of processes occurred during annealing: the formation of special boundaries (mainly $\Sigma 3$ twins) of two types, low-energy and migrating high-energy; the splitting of $\Sigma 9$ special boundaries into two $\Sigma 3$ twins; the migration of common boundaries and their local transformation into special boundaries in some local place; and the splitting of common boundaries into two special boundaries, $\Sigma 9$ and $\Sigma 3$. The migration of incoherent $\Sigma 3$ twins testifies to the high value of the grain-boundary diffusion coefficient characteristic of the stage of the abnormal growth of grains on the $d-T$ curve. The migrating boundaries were in a nonequilibrium state. The separation of $\mathrm{Cu}_{2} \mathrm{O}$ phase particles proceeds on migrating incoherent $\Sigma 3$ twins and common grain boundaries.

\section{ACKNOWLEDGMENTS}

The work was carried out within the framework of the Program of Fundamental Research of the State Academies of Sciences for 2013-2020.

\section{REFERENCES}

1. Valiev, R.Z. and Aleksandrov, I.V., Nanostrukturnye materialy, poluchennye intensivnoi plasticheskoi deformatsiei (Nanostructured Materials Synthesized by Severe Plastic Deformation), Moscow: Logos, 2000.

2. Valiev, R.Z., Estrin, Y., Horita, Z., et al., Mater. Res. Lett., 2016, vol. 4, no. 1, p. 1.

3. Amouyal, Y. and Rabkin, E., Acta Mater., 2007, vol. 55, p. 6681 .

4. Nokhrin, A.V., Tech. Phys. Lett., 2012, vol. 38, no. 7, p. 630 .

5. Ovid'ko, I.A., Fiz. Mekh. Mater., 2009, vol. 8, p. 174.
6. Tsypin, M.I., Sollertinskaya, E.S., Bravets, V.V., and Daneliya, G.V., in Metallovedenie i termicheskaya obrabotka (Metallography and Thermal Treatment), Moscow: Metallurgiya, 1978, p. 9.

7. Gorelik, S.S., Rekristallizatsiya metallov $i$ splavov (Recrystallization of Metals and Alloys), Moscow: Metallurgiya, 1967.

8. Gindraux, G. and Form, W., J. Inst. Met., 1973, no. 101 , p. 85.

9. Randle, V. and Davies, R., Mater. Sci. Technol., 1999, vol. 15 , p. 750 .

10. Randle, V., Acta Mater., 1999, vol. 47, no. 15, p. 4187.

11. Perevalova, O.B., Konovalova, E.V., Koneva, N.A., and Kozlov, E.V., Vliyanie atomnogo uporyadocheniya na zernogranichnye ansambli GTSK-tverdykh rastvorov (Influence of Atomic Ordering on the Grain-Boundary Ensembles of FCC Solid Solutions), Tomsk: NTL, 2014.

12. Ivanov, K.V. and Naydenkin, E.V., Mater. Sci. Eng. A, 2014, vol. 608, p. 123.

13. Zisman, A.A. and Rybin, V.V., Fiz. Met. Metalloved., 1989, vol. 68 , no. 2 , p. 264.

14. Konovalova, E.V., Perevalova, O.B., Koneva, N.A., and Kozlov, E.V., Metallofiz. Noveishie Tekhnol., 2001, vol. 23, no. 5, p. 655 .

15. Andreeva, A.V. and Fionova, L.K., Fiz. Met. Metalloved., 1981, vol. 52, no. 3, p. 539.

16. Lim, L.C. and Ray, R., Acta Metall., 1984, vol. 32, no. 8, p. 1177.

17. Fang, X., Zhang, K., Guo, H., Mater. Sci. Eng. A, 2008, vol. 487, p. 7.

18. Kopetskii, Ch.V., Orlov, A.N., and Fionova, L.K., Granitsy zeren $v$ chistykh metallakh (Grain Boundaries in Pure Metals), Moscow: Nauka, 1987.

19. Gertsman, V.Yu., Danilenko, V.N., and Valiev, R.Z., Metallofizika, 1990, vol. 12, no. 3, p. 120.

20. Kolobov, Yu.R., Diffuzionno-kontroliruemye protsessy na granitsakh zeren $i$ plastichnost' metallicheskikh polikristallov (Diffusion-Controlled Processes at the Grain Boundaries and the Plasticity of Metallic Polycrystals), Novosibirsk: Nauka, 1998.

21. Kaibyshev, O.A. and Valiev, R.Z., Granitsy zeren $i$ svoistva metallov (Grain Boundaries and the Properties of Metals), Moscow: Metallurgiya, 1987.

Translated by L. Mosina 